\title{
The Effect of Temperature on Bisphenol: An Elution from Dental Resins
}

\author{
${ }^{1}$ Didem Atabek, ${ }^{2}$ Itir Aydintug, ${ }^{3}$ Alev Alaçam, ${ }^{4}$ Aysel Berkkan
}

\section{ABSTRACT}

Aim: Bisphenol A (BPA) elution from baby bottles into content has been of great public interest and debate in recent year. Uncontrolled BPA elution due to temperature increase may create a risk factor for human health. However, dental resins that are used in pediatric dentistry also have BPA derivatives. The aim of this study is to evaluate BPA elution from dental resins and to determine the effect of temperature increase on this elution.

Materials and methods: Four dental resins containing BPA derivatives (Filtek Z250, Filtek Supreme XT, Fissurit FX, and Admira) and a control group (BPA free G-aenial) were used in this study. Each specimen was stored in $2 \mathrm{ml}$ of $75 \%$ ethanolwater solution at $37^{\circ} \mathrm{C}$. Water at a temperature of $59^{\circ} \mathrm{C} \pm 1{ }^{\circ} \mathrm{C}$ (preferred temperature of hot drinks) was added to the study samples at certain time intervals $(1,6,24$ hours and 2, 3, 4, 5 and 6 days). The methanol samples were analyzed using high-performance liquid chromatography (HPLC). Data was analyzed using multivariate and repeated measures analysis of variance $(p<0.05)$.

Results: The study samples generally eluted more BPA than the control samples $(p<0.05)$. The greatest amount of BPA for an individual time period was measured after 6 hours for the groups A to D; the same was found after 24 hours for group $E$.

Conclusion: While the BPA elution levels evaluated in the study samples were more than control samples, all measured values were under the reference levels and the amounts do not constitute a risk.

Clinical significance: Resin-based dental materials can act as a source of BPA (within safety margins), especially when they react with hot water.

Keywords: Resin, BPA, HPLC, Cytotoxicity.

How to cite this article: Atabek D, Aydintug I, Alaçam A, Berkkan A. The Effect of Temperature on Bisphenol: An Elution from Dental Resins. J Contemp Dent Pract 2014;15(5):576-580.

Source of support: Nil

Conflict of interest: None

\footnotetext{
${ }^{1,2}$ Research Assistant, ${ }^{3}$ Professor, ${ }^{3}$ Associate Professor

${ }^{1-3}$ Department of Pedodontics, Faculty of Dentistry, Gazi University, Ankara, Turkey

${ }^{4}$ Department of Analytical Chemistry Division, Faculty of Pharmacy, Gazi University, Ankara, Turkey
}

Corresponding Author: Didem Atabek, Research Assistant Department of Pedodontics, Faculty of Dentistry, Gazi University Ankara, Turkey, Phone: 905052526574, e-mail: dtdidem@ hotmail.com

\section{INTRODUCTION}

Bisphenol A (BPA) is a synthetic chemical compound that was first synthesized in 1891. Its estrogenic properties were recognized as early as the 1930s. Today, BPA is the main chemical used to manufacture polycarbonate plastics and epoxy resins. ${ }^{1}$ BPA can hydrolyze and leach from polycarbonate plastics and epoxy resins into food and liquids in contact with a container. The leaching is increased by high temperature, and acidic and basic conditions. ${ }^{2}$ In fetuses, infants and children, BPA can cause neurological-behavioral disorders and early puberty in girls, and can affect the prostate and mammary glands. ${ }^{2,3}$ Because human exposure to BPA is so widespread in industrialized countries, patients' questions are increasing about BPA exposure and their children's health.

In dentistry, BPA is used in the synthesis of matrix monomers, such as dimethacrylate monomers for dental composite resins and fissure sealants. ${ }^{4}$ Dental resins primarily comprise BPA derivatives rather than pure BPA. ${ }^{1}$ BPA glycidyl dimethacrylate (Bis-GMA) is the derivative most frequently used as the base of the resins. Other BPA derivatives traditionally used in dental resins are BPA dimethacrylate (Bis-DMA), BPA diglycidylether (BADGE), BPA ethoxylate dimethacrylate (Bis-EMA), and urethanemodified Bis-GMA. ${ }^{5}$ The estrogenic receptor-mediated effects of BPA and related biphenyls make their detection an important issue. To date, studies have reported the presence of BPA in saliva after placement of dental sealants or composites even though pure BPA is not a component of dental resin. ${ }^{1,3,5,6}$ BPA-based epoxy resins are relatively stable, but during the setting period of dental resins, there may be incomplete conversion to polymer and chemicals. Bis-DMA and Bis-GMA might leach into the salivary fluid of the oral cavity. ${ }^{6,7}$ Through the salivary esterases, Bis-DMA hydrolyzes into BPA, whereas Bis-GMA does not undergo this reaction. ${ }^{1}$ It has been stated that BPA and Bis-DMA are responsible for the exposure of BPA from composite resins and sealants. ${ }^{7,8}$ The US Environmental Protection Agency (EPA) reference range for acceptable daily BPA exposure is set at $<50 \mu \mathrm{g} / \mathrm{kg}$ body weight $/$ day. ${ }^{1}$ In previous studies, BPA eluted from dental resins has been reported under reference level, but the effect of temperature has not been evaluated. ${ }^{1,3,5-8}$ 
The aim of this study is to evaluate BPA elution from dental resins and to determine the effect of temperature increase on this elution.

\section{MATERIALS AND METHODS}

Four dental resins containing BPA derivatives (Group A: Filtek Z250, group B: Filtek Supreme XT, Group C: Fissurit FX and group D: Admira) and a control group [Group E: G-aenial (negative control, BPA free)] were used in this study (Table 1). The standardized samples of each group $(\mathrm{n}=20)(6 \mathrm{~mm}$ in diameter, $2 \mathrm{~mm}$ high) were prepared using Teflon molds and polymerized for 40 seconds using a blue light-emitting diode (Hilux Ledmax 550) according to the manufacturer's directions. After polymerization, the sample surfaces were washed for 30 seconds with an airwater and polishing was performed using rubber polishers. The surfaces were cleaned with cotton pellets.

The BPA released from dental resins at certain time intervals (1, 6, 24 hours, and 2, 3, 4, 5 and 6 days) was determined with high-performance liquid chromatography (HPLC, Agilent Technologies 1200 series). BPA was purchased from Aldrich-Chemie (Germany). Glass syringes and glass tubes were employed throughout the sampling to avoid a contamination of BPA. Methanol and ethanol solutions were the HPLC grade. Each dental resin was prepared twice [control $(\mathrm{n}=10)$ and study $(\mathrm{n}=10)$ samples]. First one was stored in $2 \mathrm{ml}$ of $75 \%$ ethanol-water solution at 37 $\pm 1^{\circ} \mathrm{C}$ at certain time interval. The other one was heated to $59 \pm 1^{\circ} \mathrm{C}$ (commonly preferred temperature of hot drinks). The solutions were filtrated and analyzed with HPLC. For the analysis of BPA with HPLC, we used a C-18 column and a UV detector at $278 \mathrm{~nm}$ wavelength. The ratio of methanol:water (60:40) solvent system was used as mobile phase at the flow rate of $1 \mathrm{ml} / \mathrm{min}$. We used a temperature of $25^{\circ} \mathrm{C}$ and an injection volume of $20 \mu$. We used solutions of BPA standards in ethanol and deionized water mixture by HPLC at concentrations between 2.5 and $15 \mathrm{mg} / \mathrm{l}$. The equation of the external calibration graph obtained by linear regression was $\mathrm{y}=15.047 \mathrm{C}+3.66(\mathrm{R} 2=0.9991)$, where $\mathrm{y}$ is the peak area of BPA and $\mathrm{C}$ is the concentration of BPA in $\mathrm{mg} / \mathrm{l}$. Data was analyzed using multivariate and repeated measures analysis of variance $(\mathrm{p}<0.05)$.

\section{RESULTS}

The limit of detection and limit of quantification were found to be $0.06 \mathrm{mg} / 1$ and $0.18 \mathrm{mg} / \mathrm{l}$ respectively. Retention time in the HPLC chromatogram for BPA standard was 21.3 minutes (Fig. 1). The chromatogram of BPA released from dental resins was shown in Figure 2.

The mean concentrations $(\mu \mathrm{g} / \mathrm{ml})$ of eluted BPA for each time interval are shown in Table 2 and Figure 3. No BPA was detected in the negative control group (BPA-free) samples.

In all groups and for all time intervals, BPA elution was detected. A statistically significant increase in BPA elution was detected in the study samples of all groups $(p<0.05)$, except in the 24 hours analysis of group A, 2 days and 5 days analysis of group B, and the 6 days analysis of group C. The highest elution of BPA occurred in the group C samples. For the control group samples, the greatest amounts of eluted BPA for an individual time period were measured after 6 hours for groups A, B and D; whereas the same was found after 1 day for group C. Among the study samples, the greatest amounts of eluted BPA were measured after 1 hour for group B, 6 hours for groups A and D, and 2 days for group $\mathrm{C}$. The differences among time intervals showed certain inconsistencies in the samples.

\section{DISCUSSION}

In dentistry, BPA is a common ingredient in restorative materials. Since the 1960s, when Bis-GMA-based restorative materials were first used in dentistry, studies have assessed the cytotoxic properties of resins. ${ }^{9}$ Although it is known

Table 1: Materials used in the study

\begin{tabular}{|c|c|c|c|}
\hline Company & Composite name & Type & Composition \\
\hline $\begin{array}{l}\text { 3M ESPE } \\
\text { St.Paul,USA }\end{array}$ & $\begin{array}{l}\text { Filtek Z250 } \\
\text { (Group A) }\end{array}$ & Microhybrid & $\begin{array}{l}\text { BPA ethoxylate dimethacrylate; diurethane dimethacrylate; } \\
\text { Bis-GMA; TEGDMA }\end{array}$ \\
\hline $\begin{array}{l}\text { 3M ESPE } \\
\text { St.Paul,USA }\end{array}$ & $\begin{array}{l}\text { Filtek Supreme XT } \\
\text { (Group B) }\end{array}$ & Nanohybrid & $\begin{array}{l}\text { Diurethane dimethacrylate (UDMA), } \\
\text { Bisphenol A diglycidylether methacrylate (Bis-GMA), } \\
\text { Bisphenol A, } \\
\text { polyethylene glycol diether dimethacrylate (Bis-EMA), } \\
\text { triethylene glycol dimethacrylate (TEGDMA), } \\
\text { silane treated ceramic and silica, water }\end{array}$ \\
\hline $\begin{array}{l}\text { Voco GmbH } \\
\text { Germany }\end{array}$ & $\begin{array}{l}\text { Fissurit FX } \\
\text { (Group C) }\end{array}$ & Fissure sealent & Bis-GMA, Diurethane dimethacrylate \\
\hline $\begin{array}{l}\text { Voco GmbH } \\
\text { Germany }\end{array}$ & $\begin{array}{l}\text { Admira } \\
\text { (Group D) }\end{array}$ & Ormocer & $\begin{array}{l}\text { Dimethacrylates (UDMA, BisGMA), } \\
\text { Ormocers, silicate, fillers, catalyst system, auxiliaries }\end{array}$ \\
\hline $\begin{array}{l}\text { GC } \\
\text { UK Ltd }\end{array}$ & $\begin{array}{l}\text { G-aenial Posterior } \\
\text { (Group E) }\end{array}$ & $\begin{array}{l}\text { Universal posterior } \\
\text { composite }\end{array}$ & Bis-GMA free \\
\hline
\end{tabular}




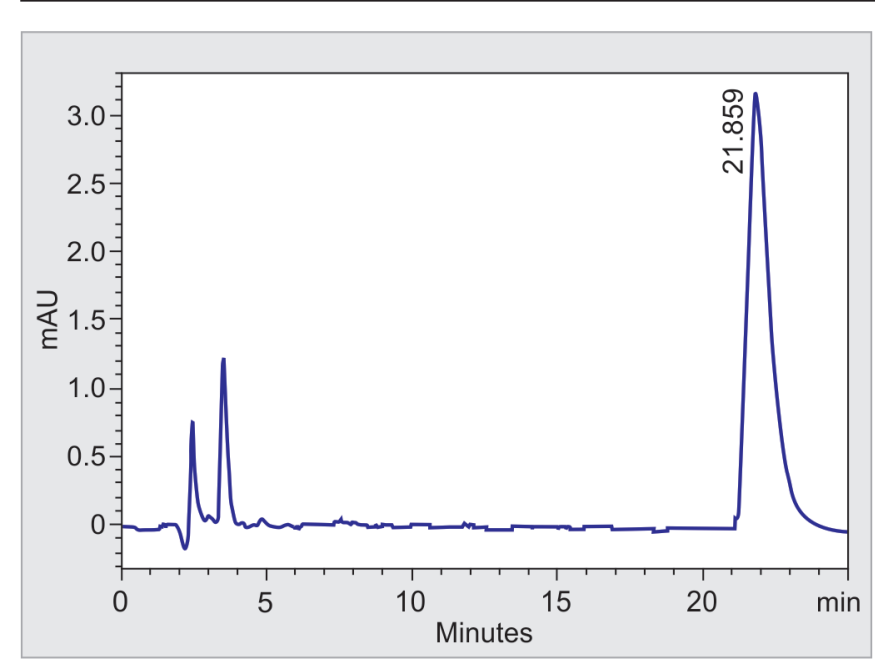

Fig. 1: HPLC chromatogram of $10 \mathrm{mg} / \mathrm{l} \mathrm{BPA}$ standard

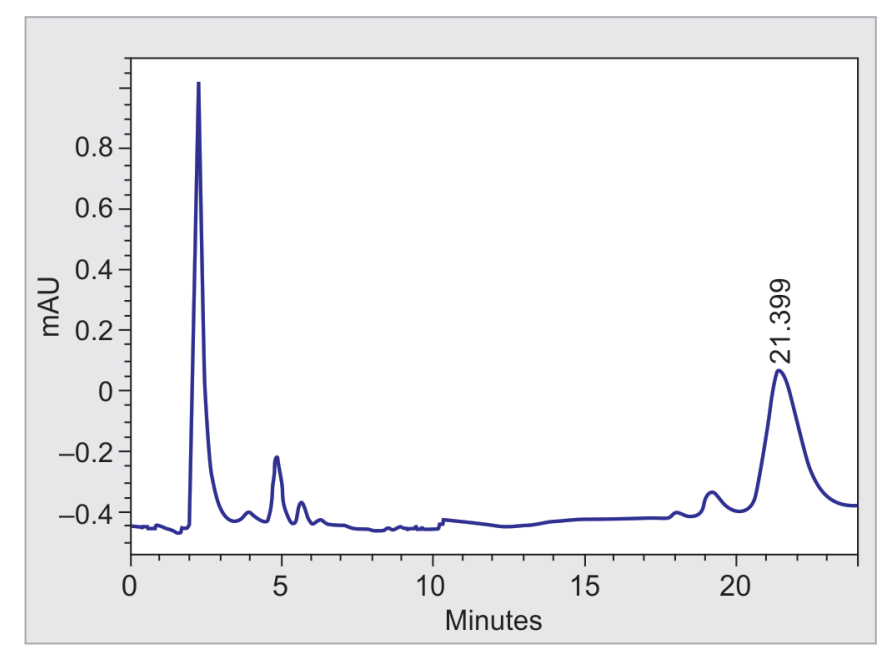

Fig. 2: HPLC chromatogram of BPA released from dental resin

Table 2: Mean concentrations $(\mu \mathrm{g} / \mathrm{ml})$ of eluted BPA for each time interval

\begin{tabular}{|c|c|c|c|c|c|}
\hline & Group A & Group B & Group C & Group D & $p$-value ${ }^{a}$ \\
\hline \multicolumn{6}{|l|}{1 hour } \\
\hline- & $4.8(1.75)^{\mathrm{A}}$ & $5.4(5.75)^{\mathrm{BC}}$ & $3.4(1.75)^{\mathrm{B}}$ & $2.6(1.80)^{\mathrm{AC}}$ & 0.006 \\
\hline+ & $7.3(2.55)^{\mathrm{DE}}$ & $12.3(13.00)^{\mathrm{D}}$ & $12.8(3.55)^{\mathrm{E}}$ & $8.7(4.15)$ & 0.019 \\
\hline$p$-value ${ }^{b}$ & 0.008 & 0.006 & 0.008 & 0.008 & \\
\hline \multicolumn{6}{|l|}{6 hours } \\
\hline- & $6.3(1.45)^{\mathrm{AE}}$ & $6.2(0.65)^{\mathrm{BC}}$ & $4.3(1.35)^{\mathrm{BEF}}$ & $2.9(1.75)^{\mathrm{ACF}}$ & 0.002 \\
\hline+ & $10.3(2.25)^{\mathrm{E}}$ & $12.0(2.50)^{\mathrm{C}}$ & $12.7(6.80)^{\mathrm{EF}}$ & $9.3(2.90)^{C F}$ & 0.007 \\
\hline$p$-value ${ }^{b}$ & 0.008 & 0.008 & 0.008 & 0.008 & \\
\hline \multicolumn{6}{|l|}{1 day } \\
\hline- & $3.1(2.20)^{\mathrm{DE}}$ & $5.6(4.95)^{C D}$ & $8.0(4.70)^{E F}$ & $2.2(1.65)^{C F}$ & 0.002 \\
\hline+ & $4.7(1.85)^{\mathrm{ADE}}$ & $11.9(2.25)^{\mathrm{CD}}$ & $12.9(10.55)^{\mathrm{EF}}$ & $8.1(3.05)^{\mathrm{ACF}}$ & 0.002 \\
\hline$p$-value ${ }^{b}$ & 0.056 & 0.006 & 0.005 & 0.008 & \\
\hline \multicolumn{6}{|l|}{2 days } \\
\hline- & $3.3(3.60)^{\mathrm{A}}$ & $5.7(4.80)^{\mathrm{BC}}$ & $1.4(1.15)^{\mathrm{B}}$ & $0.9(0.75)^{\mathrm{AC}}$ & 0.003 \\
\hline+ & $10.2(7.70)^{\mathrm{A}}$ & $9.8(9.5)^{C}$ & $13.9(4.05)^{F}$ & $5.2(2.50)^{\mathrm{ACF}}$ & 0.015 \\
\hline$p$-value ${ }^{b}$ & 0.016 & 0.056 & 0.008 & 0.008 & \\
\hline \multicolumn{6}{|l|}{3 days } \\
\hline- & $4.1(2.25)^{\mathrm{AD}}$ & $2.5(1.40)^{C D}$ & $3.5(1.65)^{F}$ & $1.1(0.25)^{\mathrm{ACF}}$ & 0.003 \\
\hline+ & $7.2(1.55)^{\mathrm{AE}}$ & $7.1(5.00)^{\mathrm{C}}$ & $12.8(1.10)^{\mathrm{EF}}$ & $4.6(1.70)^{\mathrm{ACF}}$ & 0.002 \\
\hline$p$-value ${ }^{b}$ & 0.016 & 0.008 & 0.008 & 0.008 & \\
\hline \multicolumn{6}{|l|}{4 days } \\
\hline- & $1.2(1.35)$ & $2.2(1.35)$ & $0.9(0.5)$ & $1.1(1.05)$ & 0.348 \\
\hline+ & $3.4(3.80)^{\mathrm{E}}$ & $3.3(0.55)^{B}$ & $8.9(2.75)^{\mathrm{BE}}$ & $3.6(11.00)$ & 0.038 \\
\hline$p$-value ${ }^{b}$ & 0.032 & 0.008 & 0.008 & 0.008 & \\
\hline \multicolumn{6}{|l|}{5 days } \\
\hline- & $1.1(1.05)$ & $1.4(1.20)$ & $0.8(0.30)$ & $1.3(0.95)$ & 0.120 \\
\hline+ & $2.3(2.95)$ & $1.7(0.60)$ & $2.7(0.85)$ & $2.7(1.90)$ & 0.050 \\
\hline$p$-value ${ }^{b}$ & 0.008 & 0.421 & 0.008 & 0.016 & \\
\hline \multicolumn{6}{|l|}{6 days } \\
\hline- & $0.9(0.25)$ & $1.0(1.15)$ & $0.4(1.05)$ & $1.4(0.90)$ & 0.177 \\
\hline+ & $1.6(1.35)$ & $2.9(1.20)^{B}$ & $1.5(0.60)^{\mathrm{BF}}$ & $3.1(1.40)^{F}$ & 0.036 \\
\hline$p$-value ${ }^{b}$ & 0.008 & 0.032 & 0.095 & 0.008 & \\
\hline
\end{tabular}

${ }^{\mathrm{a} C}$ Comparisons between the materials in the measurement times, Kruskal-Wallis test; ${ }^{\mathrm{b}}$ Comparisons in terms of heat within the materials at

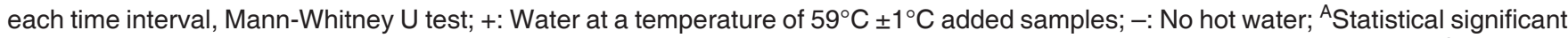
difference between the groups A and D $(p<0.05)$; ${ }^{B}$ Statistical significant difference between the groups B and $C(p<0.05)$; ${ }^{C}$ Statistical significant difference between the groups $C$ and $D(p<0.05)$; ${ }^{D}$ Statistical significant difference between the groups $A$ and $B(p<0.05)$;

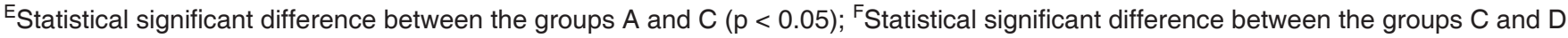
$(p<0.05)$; The capital letters in the same line mean statistically significant differences $(p<0.05)$ 


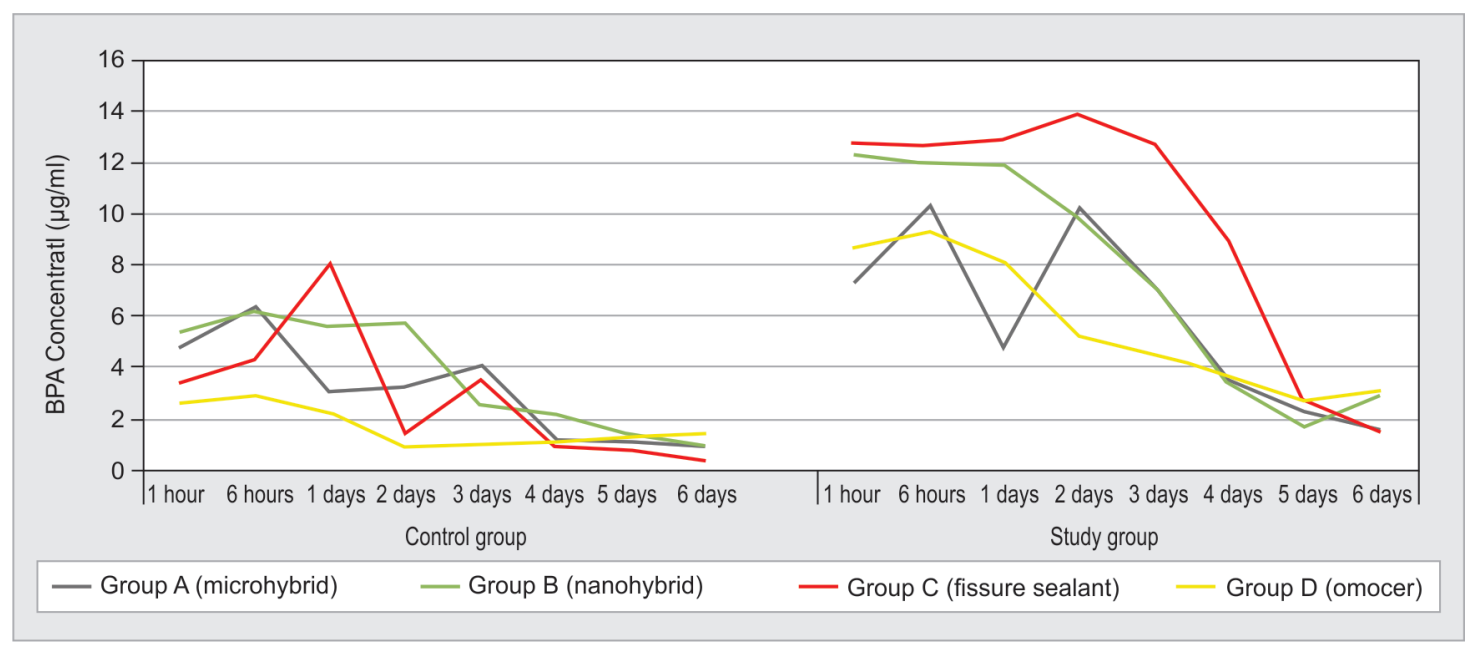

Fig. 3: Elution levels of BPA from resin-based dental materials for each time interval

from time immemorial, the importance of exposure to BPA is now on the agenda. There is a growing body of literature examining the health effects of BPA exposure in humans. BPA leaching from plastics or epoxy resin coatings is related to high temperature and heating time. ${ }^{2}$ The issue is whether the release of BPA is affected by hot liquid consumption of patients who undergo composite restorations and/or fissure sealants. The literature does not answer this question, so this is the first and basic study on this topic.

Recent studies on this topic evaluated the content of BPA, Bis-GMA and Bis-DMA in saliva after application of dental sealants and composites. In vitro ${ }^{7,10,11}$ and in vivo $^{3,5,6,12}$ studies showed elution of BPA and BPA derivatives, by varying the rates and periods. This variability in results seems to reflect differences in methodologies and the materials used in the studies. To detect the elution of BPA, the authors used gas chromatography,${ }^{13}$ mass spectroscopy,${ }^{12}$ and high-performance liquid chromatography (HPLC). ${ }^{7}$ HPLC studies have varied based on the medium, such as water, ethanol or human saliva. ${ }^{10}$ Human saliva seems to be the best choice to mimic the environment of the mouth, but in published in vitro studies, only Schmalz et al used human saliva. ${ }^{10}$ Initially, we planned to use human saliva as the medium of HPLC as well, but may be due to the intensity of the saliva, the HPLC did not work and broke down. We changed the methodology, and samples were stored in the $75 \%$ ethanol solution, approved by the US Food and Drug administration as a saliva substitute and commonly used as an organic elution medium. ${ }^{14}$

The present study tested BPA derivatives containing microhybrid (Group A: Filtek Z250), nanohybrid (Group B: Filtek Supreme XT) Ormocer (Group D: Admira) resin-based composites, a fissure sealant (Group C: Fissurit FX), and a BPA-free resin-based composite [Group E: G-aenial (negative control)]. In accordance with some studies, ${ }^{3,5,6,10,15-17}$ the chemical analysis in the present study concentrated on the detection of BPA because it is a known estrogenic. To evaluate the effect of temperature on BPA elution, the temperature as set according to Lee and O’Mahony, ${ }^{18}$ who reported mean preferred temperature for drinking was around $59 \pm 1^{\circ} \mathrm{C}$.

Although, the results of the present study showed certain inconsistencies in the samples, BPA was detected in all groups except for the control group (BPA-free). Increased temperature increases BPA elution, ${ }^{2,19,20}$ and in the present study, samples showed significantly increased BPA elution compared to the control samples $(\mathrm{p}<0.05)$. The elution of the fissure sealant group compared to the others was especially significant. Rueggeberg et $\mathrm{al}^{21}$ reported that pit and fissure sealants have the greatest potential to leave uncured resin components. Because sealants are cured without an occlusal matrix, oxygen at the restoration inhibits the setting reaction. In the present study, to minimize BPA elution, all sealant surfaces were washed for 30 seconds with an airwater, polishing was performed using rubber polishers, and the surfaces were cleaned with cotton pellets. The results showed that oxygen layer that inhibits the setting reaction may induce the highest BPA elution from the fissure sealant group. Not including the fissure sealant group (Group C), the greatest elution of BPA occurred in the nanohybrid Filtek Supreme XT (Group B) followed by the microhybrid Filtek Z250 (Group A) and Ormocer Admira (Group D), yet values were similar. The results of the present study are supported by Tabaatabaee et al, ${ }^{22}$ Polydorou et al, ${ }^{11}$ and Sideridou et $\mathrm{al},{ }^{23}$ who also reported more BPA elution from nanohybrid resin-based composites. Filtek Supreme XT contains 70 to $80 \mathrm{wt} \%$ nanohybrid fillers whereas Filtek Z250 contains 75 to $85 \mathrm{wt} \%$ of microhybrid fillers. More resin per wt $\%$ in the nanohybrid could be the cause of greater BPA elution. ${ }^{11,23}$

In vitro studies have shown that most of the unpolymerized monomers of Bis-GMA leached 24 hours after setting. ${ }^{9,14}$ As in Manojlovic et al,,${ }^{14}$ in the present study, less 
elution occurred after 1 hour compared to 6 and 24 hours. But study samples of nanohybrid Filtek Supreme XT (Group B) had the highest elution after 1 hour. This may be due to increased temperature creating a more incomplete monomer to polymer conversion. The elution of BPA began to decrease after 6 hours for the samples of groups A, B and D, whereas those of group $\mathrm{C}$ began to decrease after 24 hours. In addition, the 5-day values were similar.

The results of this study pose a question for both clinicians and patients because after the application of dental composite resins or fissure sealants, drinking hot liquid could lead to BPA elution. The BPA elution levels evaluated in the study samples or control samples were under the reference levels. So, although a temperature increase can cause more BPA elution, the amounts do not constitute a risk. Further studies on this topic are required to provide more clear answers to the patients and clinicians.

\section{CONCLUSION}

Although the eluted levels are within safety margins $(<50$ $\mu \mathrm{g} / \mathrm{kg}$ body weight/day), resin-based dental materials act as a source of BPA, especially when they react with hot water.

\section{CLINICAL SIGNIFICANCE}

Resin-based dental materials can act as a source of BPA, especially when they react with hot water.

In the light of similar further studies, may be clinicians, will advise not to drink any hot liquid for a while after application of a composite or fissure sealant restorations.

\section{REFERENCES}

1. Fleisch AF, Sheffield PE, Chinn C, Edelstein BL, Landrigan PJ. Bisphenol $\mathrm{A}$ and related compounds in dental materials. Pediatrics 2010 Oct;126(4):760-768.

2. Braun JM, Hauser R. Bisphenol A and children's health. Curr Opin Pediatr 2011 Apr;23(2):233-239.

3. Joskow R, Barr DB, Barr JR, Calafat AM, Needham LL, Rubin C. Exposure to bisphenol A from bisglycidyl dimethacrylate-based dental sealants. J Am Dent Assoc 2006 Mar;137(3):353-362.

4. Azarpazhooh A, Main PA. Is there a risk of harm or toxicity in the placement of pit and fissure sealant materials? A systematic review. J Can Dent Assoc 2008 Mar;74(2):179-183.

5. Arenholt-Bindslev D, Breinholt V, Preiss A, Schmalz G. Timerelated bisphenol-A content and estrogenic activity in saliva samples collected in relation to placement of fissure sealants. Clin Oral Investig 1999 Sep;3(3):120-125.

6. Fung EY, Ewoldsen NO, St Germain HAJr, Marx DB, Miaw CL, Siew C, Chou HN, Gruninger SE, Meyer DM. Pharmacokinetics of bisphenol A released from a dental sealant. J Am Dent Assoc $2000 \mathrm{Jan} ; 131(1): 51-58$.

7. Pulgar R, Olea-Serrano MF, Novillo-Fertrell A, Rivas A, Pazos P, Pedraza V, Navajas JM, Olea N. Determination of bisphenol A and related aromatic compounds released from Bis-GMAbased composites and sealants by high performance liquid chromatography. Environ Health Perspect 2000 Jan;108(1): 21-27.

8. Söderholm KJ, Mariotti A. Bis-GMA-based resins in dentistry: are they safe? J Am Dent Assoc 1999 Feb;130(2):201-209.

9. Olea N, Pulgar R, Pérez P, Olea-Serrano F, Rivas A, NovilloFertrell A, Pedraza V, Soto AM, Sonnenschein C. Estrogenicity of resin-based composites and sealants used in dentistry. Environ Health Perspect 1996 Mar;104(3):298-305.

10. Schmalz G, Preiss A, Arenholt-Bindslev D. Bisphenol-A content of resin monomers and related degradation products. Clin Oral Investig 1999 Sep;3(3):114-119.

11. Polydorou O, König A, Hellwig E, Kümmerer K. Long-term release of monomers from modern dental-composite materials. Eur J Oral Sci 2009 Feb;117(1):68-75.

12. Sasaki N, Okuda K, Kato T, Kakishima H, Okuma H, Abe K, Tachino H, Tuchida K, Kubono K. Salivary bisphenol-A levels detected by ELISA after restoration with composite resin. J Mater Sci Mater Med 2005 Apr;16(4):297-300.

13. Manabe A, Kaneko S, Numazawa S, Itoh K, Inoue M, Hisamitsu H, Sasa R, Yoshida T. Detection of bisphenol-A in dental materials by gas chromatography-mass spectrometry. Dent Mater J 2000 Mar;19(1):75-86.

14. Manojlovic D, Radisic M, Vasiljevic T, Zivkovic S, Lausevic M, Miletic V. Monomer elution from nanohybrid and ormocer-based composites cured with different light sources. Dent Mater 2011 Apr;27(4):371-378.

15. Van Landuyt KL, Nawrot T, Geebelen B, De Munck J, Snauwaert J, Yoshihara K, Scheers H, Godderis L, Hoet P, Van Meerbeek B. How much do resin-based dental materials release? A metaanalytical approach. Dent Mater 2011 Aug;27(8):723-747.

16. Eliades T, Voutsa D, Sifakakis I, Makou M, Katsaros C. Release of bisphenol-A from a light-cured adhesive bonded to lingual fixed retainers. Am J Orthod Dentofacial Orthop 2011 Feb;139(2):192-195.

17. Darmani H, Al-Hiyasat AS, Milhem MM. Cytotoxicity of dental composites and their leached components. Quintessence Int 2007 Oct;38(9):789-795.

18. Lee HS, O’Mahony M. At what temperature do consumers like to drink coffee?: Mixing methods. J Food Sci 2002 Sep;67(7): 2774-2777.

19. Geens T, Aerts D, Berthot C, Bourguignon JP, Goeyens L, Lecomte P, Maghuin-Rogister G, Pironnet AM, Pussemier L, Scippo ML, et al. A review of dietary and non-dietary exposure to bisphenol-A. Food Chem Toxicol 2012 Oct;50(10):3725-3740.

20. Molina-García L, Fernández-de Córdova ML, Ruiz-Medina A. Analysis of Bisphenol A in milk by using a multicommuted fluorimetric sensor. Talanta 2012 Jul 15;96:195-201.

21. Rueggeberg FA, Dlugokinski M, Ergle JW. Minimizing patients' exposure to uncured components in a dental sealant. J Am Dent Assoc 1999 Dec;130(12):1751-1757.

22. Tabatabaee MH, Mahdavi H, Zandi S, Kharrazi MJ. HPLC analysis of eluted monomers from two composite resins cured with LED and halogen curing lights. J Biomed Mater Res B Appl Biomater 2009 Jan;88(1):191-196.

23. Sideridou ID, Achilias DS. Elution study of unreacted Bis-GMA, TEGDMA, UDMA, and Bis-EMA from light-cured dental resins and resin composites using HPLC. J Biomed Mater Res B Appl Biomater 2005 Jul;74(1):617-626. 